\title{
Myopic Open-angle Glaucoma Prevalence in Northeast Asia: A Systematic Review and Meta-analysis of Population-based Studies
}

\author{
Yoon Jeong', Ahnul Ha ${ }^{2,3}$, Sung Ryul Shim ${ }^{4}$, Young Kook Kim ${ }^{1,2}$ \\ ${ }^{1}$ Department of Ophthalmology, Seoul National University Hospital, Seoul, Korea \\ ${ }^{2}$ Department of Ophthalmology, Seoul National University College of Medicine, Seoul, Korea \\ ${ }^{3}$ Department of Ophthalmology, Jeju National University Hospital, Jeju National University School of Medicine, Jeju, Korea \\ ${ }^{4}$ Department of Preventive Medicine, Korea University College of Medicine, Seoul, Korea
}

Purpose: Investigation of myopic open-angle glaucoma (OAG) prevalence in Northeast Asia by systematic review and meta-analysis.

Methods: Systematic PubMed, Embase and Cochrane database searches for Northeast Asian population-based studies published up to 30 November 2020 and reporting on myopia and OAG diagnosis. By random-effect models, pooled OAG prevalence in a myopic population and pooled myopic OAG prevalence in a general population were generated, with $95 \%$ confidence intervals (Cls).

Results: The meta-analysis encompassed five population-based studies in four countries $(12,830$ individuals, including 7,723 patients with myopia and 1,112 patients with OAG). In a myopic population, OAG prevalence was $4.10 \%(95 \% \mathrm{Cl}, 3.00-5.70$; $\left.I^{2}=93 \%\right)$; in a general population, myopic OAG prevalence was $1.10 \%\left(95 \% \mathrm{Cl}, 0.60-1.70 ; I^{2}=94 \%\right)$. A visual examination of funnel plot symmetry raised a suspicion of publication bias. Notwithstanding, Begg and Mazumbar's adjusted rank correlation test showed no such evidence $(p=0.6242)$.

Conclusions: Our systematic review and meta-analysis returned an estimate of OAG prevalence in a myopic Northeast Asian population. Our findings will inform future glaucoma studies as well as public health guidelines for Northeast Asian populations.

Key Words: Asia; Meta-analysis; Myopia; Open-angle glaucoma; Prevalence

Myopia is an increasingly concerning public health issue, especially in East Asia, where it is already extremely

Received: June 11, $2021 \quad$ Final revision: October 18, 2021 Accepted: October 19, 2021

Corresponding Author: Young Kook Kim, MD. Department of Ophthalmology, Seoul National University Hospital, Seoul National University College of Medicine, 101 Daehak-ro, Jongno-gu, Seoul 03080, Korea. Tel: 82-2-2072-4301, Fax: 82-2-741-3187, E-mail: md092@naver.com widespread [1]. According to an estimate, the prevalence of myopia and high myopia worldwide will have increased by 2050 to nearly 5 billion and 1 billion people, respectively [2].

Glaucoma is the second leading cause of blindness globally, open-angle glaucoma (OAG) being its most common manifestation [3]. The most well-established OAG risk factor is myopia [4-7], the association between them having been exhaustively investigated. 
However, whereas the respective prevalence of myopia and glaucoma are well-known, little is confirmed as to the prevalence of their combination. One study reported that $17.2 \%$ of Italian glaucoma patients were myopic [4]; other reports, meanwhile, have shown glaucoma proportions in myopic white populations ranging from $9 \%$ to $12 \%$ [8-10]. The prevalence of OAG in a myopic Asian population has yet to be investigated. In the present systematic review and meta-analysis, we investigated OAG prevalence in myopic Northeast Asian population and myopic OAG prevalence in a general Northeast Asian population.

\section{Materials and Methods}

\section{Search strategy and selection criteria}

The systematic review and meta-analysis were performed based on a pre-specified protocol, and their methods adhered to both the MOOSE (Meta-analyses Of Observational Studies in Epidemiology) [11] and PRISMA (Preferred Reporting Items for Systematic Reviews and Meta-Analyses) guidelines [12]. Research that consist of a meta-analysis are exempt from the need for institutional review board review [13].

We systematically searched for relevant studies in the PubMed, Embase, and Cochrane Library databases. Our strategies were developed with the assistance of an academic librarian with expertise in systematic review and were based on established terminology using $\mathrm{MeSH}$ and Embase search terms whenever available. The keywords included 'glaucoma,' 'open-angle glaucoma,' 'myopia,' 'refractive error,' and 'prevalence.' All of the search details are included in Table 1. Two investigators ( $\mathrm{YJ}$ and $\mathrm{AH}$ ) conducted the search in an independent and masked manner, and any inconsistencies were resolved by discussion and consensus, or if needed, by third-party (YKK) adjudication. We also manually reviewed the retrieved articles' reference lists and identified additional relevant studies thereby. The databases were searched for any and all pertinent reports published through November 30, 2020.

\section{Study selection}

In the systematic review, the study inclusion criteria were as follows: (1) population-based and (2) evaluation of both OAG and myopia prevalence. The exclusion criteria were as follows: (1) not conducted with humans or adults, (2) narrative and/or systematic review, commentary, case report, (3) involving either secondary glaucoma or angle-closure glaucoma, (4) not conducted in Northeast Asia, (5) published in language other than English, and (6) lacking any detailed definition of OAG.

\section{Data extraction and quality assessment}

Two investigators ( $\mathrm{YJ}$ and $\mathrm{AH}$ ) extracted data in both an independent and masked fashion using a standardized data extraction method based on those employed by the Cochrane Library's Database of Systematic Reviews (The Cochrane Collaboration: Review Manager 4.1.1. Nepean, Ontario, Canada). Extracted data following entry into a

Table 1. PubMed, Cochrane, and Embase search strategy

\begin{tabular}{|c|c|c|}
\hline & \multicolumn{2}{|c|}{ Search strategy } \\
\hline & PubMed and Cochrane & Embase \\
\hline 1. Population (disease) & $\begin{array}{l}\text { "Glaucoma”[MeSH] OR “Glaucoma”[tiab] OR } \\
\text { "OAG”[tiab] OR "POAG”[tiab] }\end{array}$ & 'Glaucoma'/exp OR 'OAG' OR 'POAG' \\
\hline 2. Exposure & $\begin{array}{l}\text { "Myopia”[MeSH] OR “Myopia”[tiab] OR } \\
\text { "Myopic" [tiab] OR "Refractive errors" }[\mathrm{MeSH}] \text { OR } \\
\text { "Refractive errors"[tiab] OR "Refractive error"[tiab] }\end{array}$ & $\begin{array}{l}\text { 'Myopia'/exp OR 'Myopic' OR 'Refraction error'/ } \\
\text { exp OR 'Refractive error' OR 'Refractive errors' }\end{array}$ \\
\hline 3. Outcome & 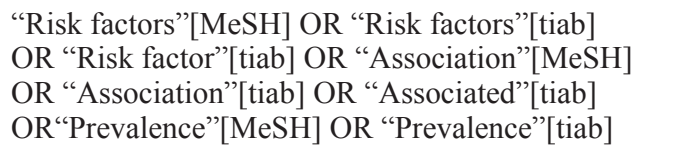 & $\begin{array}{l}\text { 'Risk factor'/exp OR 'Risk factors' OR } \\
\text { 'Determinants' OR 'Determinant' OR } \\
\text { 'Association'/exp OR 'Associated' OR 'Prevalence'/ } \\
\text { exp OR 'Prevalence' }\end{array}$ \\
\hline 4. Final search & 1 AND 2 AND 3 & 1 AND 2 AND 3 \\
\hline
\end{tabular}


dedicated database were rechecked by a third investigator (YKK). The following data were extracted: first author's name, publication year, race/ethnicity of population, study country, subject number, subjects' age and sex, OAG-diagnostic criteria, myopia definition followed, OAG patient number, myopia patient number, and number of patients with both myopia and OAG.

To assess the methodological quality of the studies, the Newcastle-Ottawa Scale for assessment of comparative nonrandomized study quality was applied (Table 2) [19-23]. Studies were additionally evaluated to determine the risks of bias related to selection, comparability, exposure/outcome, or any other factor.

\section{Statistical analysis}

Because of the anticipated high levels of heterogeneity, we used a random effect model to estimate the pooled OAG prevalence in a myopic population and the pooled myopic OAG prevalence in a general population. Inter-study heterogeneity was quantified by the $\mathrm{I}^{2}$ statistic representing the interstudy variation prevalence that can be attributed to heterogeneity rather than sampling error $[14,15]$. Values of approximately $25 \%, 50 \%$, and $75 \%$ represent low, medium, and high heterogeneity, respectively.

To qualitatively synthesize myopia degree, the prevalence of myopic OAG, and percentage of OAG among myopia, we stratified myopia into low, moderate, moderate-to-high, and high degree categories, as based on spherical equivalent (SE) refractive error up to -3 diopters (D), between -6 D and -3 D (or -4 D), lower than -3 D (or -4 D), and lower than $-6 \mathrm{D}$, respectively.

Publication bias was evaluated in two ways: (1) qualitatively by funnel plot [16], recognized as the best way to de- termine if small studies with small effect sizes are missing, and (2) quantitatively by Begg and Mazumdar's adjusted rank correlation test (a direct statistical analogue of the funnel plot), which determines if there is any significant correlation between effect estimates and their variances [17]. The absence of same would suggest unbiased study selection.

The data handling and the statistical analyses were under the purview of a single investigator (YKK) supervised by a statistician with expertise in meta-analysis (SRS). All of the $95 \%$ confidence intervals (CIs) and $p$ values were two-sided; $p<0.05$ was considered to represent statistical significance. All of the statistical analyses were performed with R ver. 4.0.4 (The R Foundation for Statistical Computing, Vienna, Austria; https://www.r-project.org/) [17,18].

\section{Results}

\section{Study inclusion}

Our systematic search identified 1,014 articles, 765 from PubMed and 249 from Embase (not in PubMed), among which, 79 were full-text reviewed. Following a thorough review, the final analysis proceeded with five studies (Fig. 1).

Five population-based studies involving a total of 26,661 individuals had been conducted in four countries: two in China [19,20], one in Japan [21], one in South Korea [22], and one in Singapore (Malay population) [23]. The number of participants varied from 2,528 to 13,831 ; the median sample size was 3,108 . The mean age in each study was $55.8 \pm 10.3$ years in Beijing, China; $63.5 \pm 8.8$ years in Shanghai, China; $58.4 \pm 11.8$ years in Japan; $55.1 \pm 0.2$ years in South Korea; and $58.2 \pm 10.9$ years in Singapore

Table 2. Quality assessment of included studies according to the Newcastle-Ottawa Scale

\begin{tabular}{lcccc}
\hline Study & Selection & Comparability & Outcome/exposure & Total score \\
\hline Suzuki et al. [21], the Tajimi study (2006) & 4 & 1 & 2 & 7 \\
Xu et al. [20], the Beijing eye study (2007) & 4 & 1 & 2 & 7 \\
Perera et al. [23], the Singapore Malay eye study (2010) & 4 & 2 & 2 & 8 \\
He et al. [19], Pudong, Shanghai study (2015) & 4 & 2 & 2 & 8 \\
Kim et al. [22], Korea National Health and Nutrition & 4 & 2 & & 8 \\
Examination Survey (2016) & & &
\end{tabular}

For each of the section (selection, comparability, and outcome/exposure), a maximum of 4, 2, and 3 points could be given, respectively. Thus, the maximum score was 9 . A higher score means higher quality. 


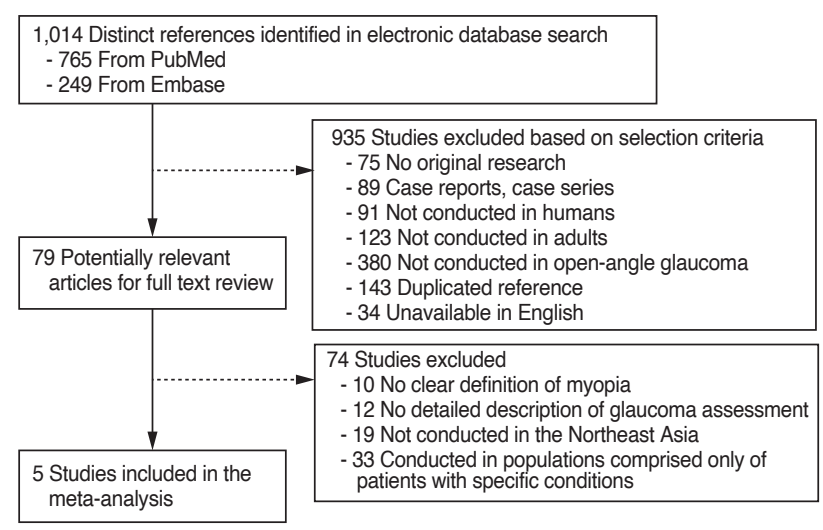

Fig. 1. Flow diagram showing study selection process for meta-analysis.

(Malay population). In three of the studies, myopia was defined according to an SE of $-0.5 \mathrm{D}[20,22,23]$, and one study reported myopia of less than -1.0 D SE [21]. One other study provided no definition of myopia [19].

In the South Korean study, the number of OAG patients was 710 , the highest among the studies. In the Chinese, Japanese, and Singaporean (Malay population) studies, the OAG patient numbers ranged between 72 and 119. The number of myopic patients, like the number of OAG patients, was highest in South Korea $(4,039)$, followed by Beijing, China (1,837). The myopic patient numbers in the three remaining studies ranged between 239 and 877 . Table 3 summarizes the characteristics of all of the studies [1923]. Table 4 lists the diagnostic criteria for glaucoma followed in each study [19-23].

\section{Estimated prevalence of myopic OAG in Northeast Asian population}

In the Northeast Asian population as a whole, the estimated prevalence of myopia ranged from $9.5 \%$ to $42.5 \%$, and that of OAG ranged from $2.8 \%$ to $5.1 \%$ (Table 3 ) [1923]. The estimated $\mathrm{OAG}$ prevalence among myopia patients ranged from $2.7 \%$ to $6.3 \%$. In South Korea, the prevalence was $6.3 \%$, the highest among the studies. The prevalence was the lowest in China (2.7\%). In the general population, the prevalence of myopic OAG ranged from $0.5 \%$ to $1.8 \%$ (Table 3) [19-23]. The estimated prevalence was $1.8 \%$ in South Korea and $0.5 \%$ in China, the highest and the lowest, respectively. In the other three studies, the estimated

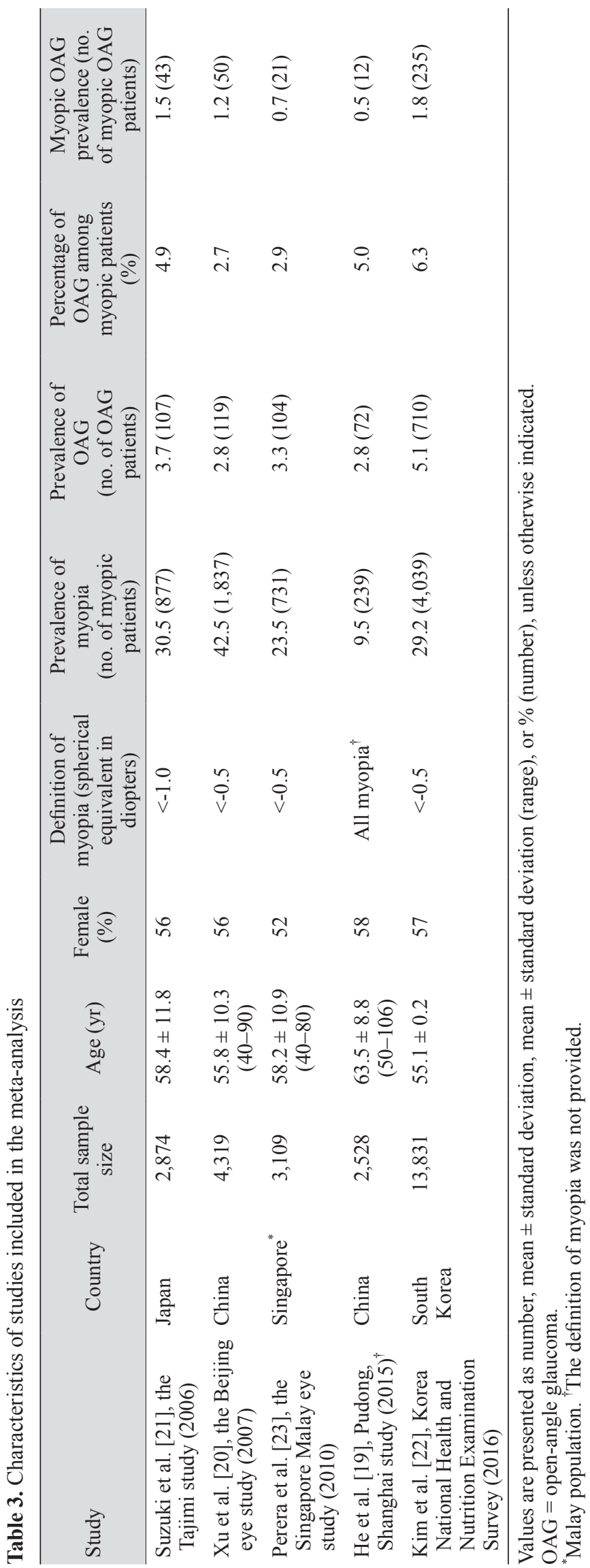


Table 4. Glaucoma diagnostic criteria for studies included in the meta-analysis

\begin{tabular}{lc}
\hline Study & \multicolumn{1}{c}{ Diagnosis of glaucoma } \\
\hline Suzuki et al. [21], the Tajimi study (2006) & CDR $\geq 0.7$ or neuroretinal rim width ${ }^{*}<0.1$ DD or asymmetry $\geq 0.2$ or \\
Ru et al. [20], the Beijing eye study (2007) & Optic disc abnormalities (a notch in the neuroretinal rim or abnormally \\
& $\begin{array}{l}\text { large cup or a localized RNFLD) and GVFD } \\
\text { CDR or CDR asymmetry 97.5th percentile or NRRW }<0.1 \text { CDR, }\end{array}$ \\
Perera et al. [23], the Singapore Malay eye study (2010) & GVFD, $>180^{\circ}$ of TM visible on gonioscopy \\
& CDR or CDR asymmetry 97.5th percentile, GVFD, gonioscopy \\
He et al. [19], Pudong, Shanghai study (2015) & Loss of neuroretinal rim with CDR $\geq 0.7$ or asymmetry $\geq 0.2$, DH, \\
Kim et al. [22], Korea National Health and Nutrition & RNFLD, GVFD on FDT, open angle by Van Herick method \\
Examination Survey (2016) &
\end{tabular}

$\mathrm{CDR}=$ cup-to-disc ratio; $\mathrm{DD}=$ disc diameter; $\mathrm{RNFLD}=$ retinal nerve fiber layer defect; GVFD = glaucomatous visual field defect; $\mathrm{NRRW}=$ neuro retinal rim width; $\mathrm{TM}=$ trabecular meshwork; $\mathrm{DH}=$ disc hemorrhage; FDT = frequency doubling technology;

*ISNT, in the order of inferior $(\mathrm{I})>\operatorname{superior}(\mathrm{S})>\operatorname{nasal}(\mathrm{N})>$ temporal $(\mathrm{T})$.

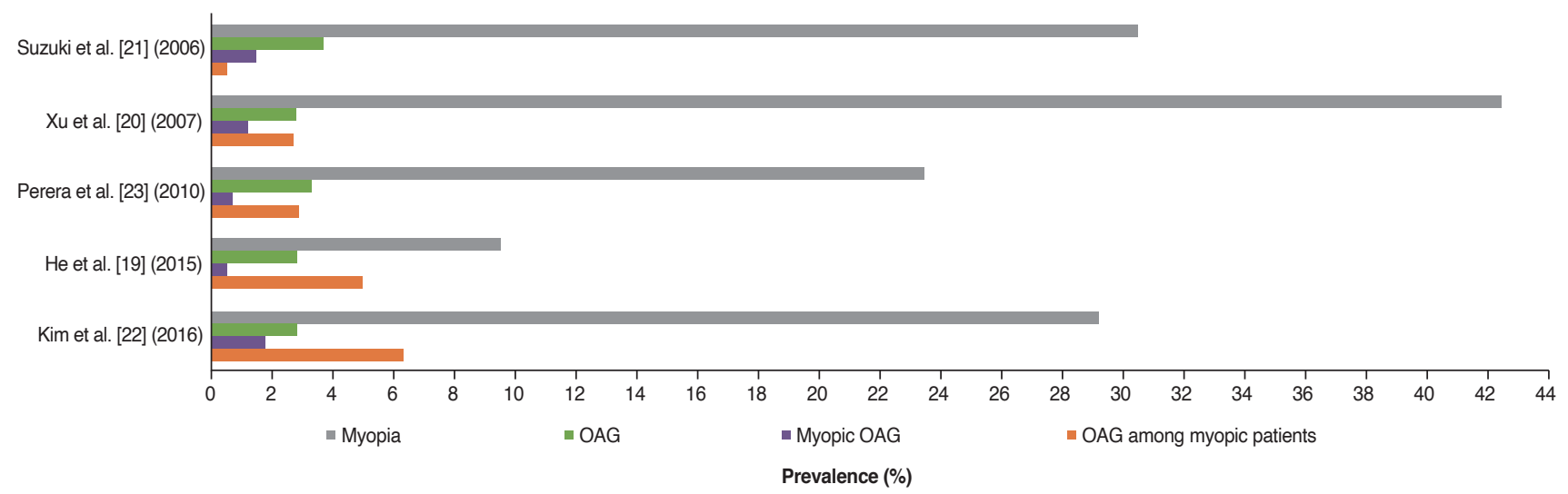

Fig. 2. Bar graphs showing prevalences of myopia, open-angle glaucoma (OAG), myopic OAG, and OAG among myopic patients.

prevalence of myopic OAG ranged between $0.7 \%$ and $1.5 \%$. The detailed results are provided in bar graphs in Fig. 2.

\section{Pooled prevalence of myopic OAG and OAG in myopia}

The overall pooled prevalence of OAG among patients with myopia was $4.10 \%$ (95\% CI, 3.00\%-5.70\%). There was significant heterogeneity of OAG prevalence in myopia $\left(\mathrm{I}^{2}=90 \%, p<0.01\right)$ (Fig. 3A). The overall pooled myopic OAG prevalence in the general population was $1.1 \%$ $(95 \%$ CI, $0.6 \%-2.1 \%)$. The pooled estimate of overall myopic OAG showed substantial heterogeneity as well $\left(\mathrm{I}^{2}=\right.$ $94 \%, p<0.01$ ) (Fig. 3B).

\section{Qualitative synthesis of OAG prevalence by myopia severity}

Four studies (except He et al. [19], Pudong, Shanghai Pudong, Shanghai study) reported both an odds ratio (OR) for any myopia and ORs by myopia severity. Table 5 shows the prevalence of OAG by myopia severity in general Northeast Asian population and percentage of OAG by myopia severity in myopic population of Northeast Asia [2023]. The prevalence of highly myopic OAG in general population was $0.15 \%$ to $0.16 \%$, that of moderately myopic OAG was $0.12 \%$ to $0.9 \%$, and that of mildly myopic OAG was $0.32 \%$ to $1.63 \%$. The percentage of OAG among patients with low myopia, moderate-to-high myopia, and high myopia was $2.24 \%$ to $4.37 \%, 2.40 \%$ to $5.33 \%$, and $6.07 \%$ to $8.68 \%$, respectively. 
A

$\begin{array}{lrrl}\text { Study } & \text { Events } & \text { Total } & \text { Random (95\% Cl) } \\ \text { Xu et al. [20] (2007) } & 50 & 1,837 & 0.027(0.020-0.036) \\ \text { Perera et al. [23] (2010) } & 21 & 731 & 0.029(0.018-0.044) \\ \text { Suzuki et al. [21] (2006) } & 43 & 877 & 0.049(0.036-0.065) \\ \text { He et al. [19] (2015) } & 12 & 239 & 0.050(0.026-0.086) \\ \text { Kim et al. [22] (2016) } & 253 & 4,039 & 0.063(0.055-0.071) \\ & & & \\ \text { Total (95\% Cl) } & & \mathbf{7 , 7 2 3} & \mathbf{0 . 0 4 1}(\mathbf{0 . 0 3 0 - 0 . 0 5 7 )} \\ \text { Heterogeneity: } \text { Tau }^{2}=0.1083 ;\left.\right|^{2}=90 \% & \end{array}$

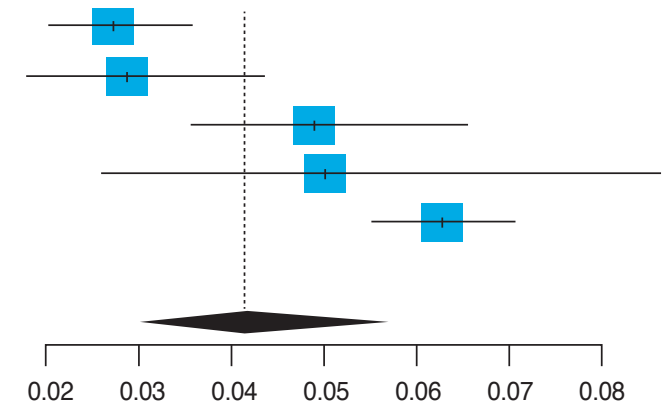

B

$\begin{array}{lrrrl}\text { Study } & \text { Events } & \text { Total } & \text { Weight } & \text { Random (95\% Cl) } \\ \text { He et al. [19] (2015) } & 12 & 2,528 & 20.4 \% & 0.005(0.002-0.008) \\ \text { Perera et al. [23] (2010) } & 21 & 3,109 & 20.2 \% & 0.007(0.004-0.010) \\ \text { Xu et al. [20] (2007) } & 50 & 4,319 & 20.0 \% & 0.012(0.009-0.015) \\ \text { Suzuki et al. [21] (2006) } & 43 & 2,874 & 18.8 \% & 0.015(0.011-0.020) \\ \text { Kim et al. [22] (2016) } & 253 & 13,831 & 20.6 \% & 0.018(0.016-0.021) \\ & & & & \\ \text { Total (95\% Cl) } & \mathbf{2 6 , 6 6 1} & \mathbf{1 0 0 . 0 \%} & \mathbf{0 . 0 1 1 ( 0 . 0 0 6 - 0 . 0 1 7 )} \\ \text { Heterogeneity: Tau }{ }^{2}<0.0001 ; l^{2}=94 \% & & \end{array}$

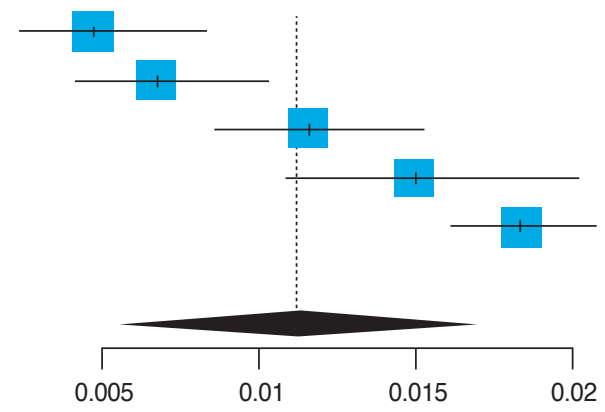

Fig. 3. Forest plot of (A) overall pooled percentage of open angle glaucoma among patients with myopia and (B) overall pooled prevalence of myopic open angle glaucoma. $\mathrm{CI}=$ confidence interval.

\section{A}

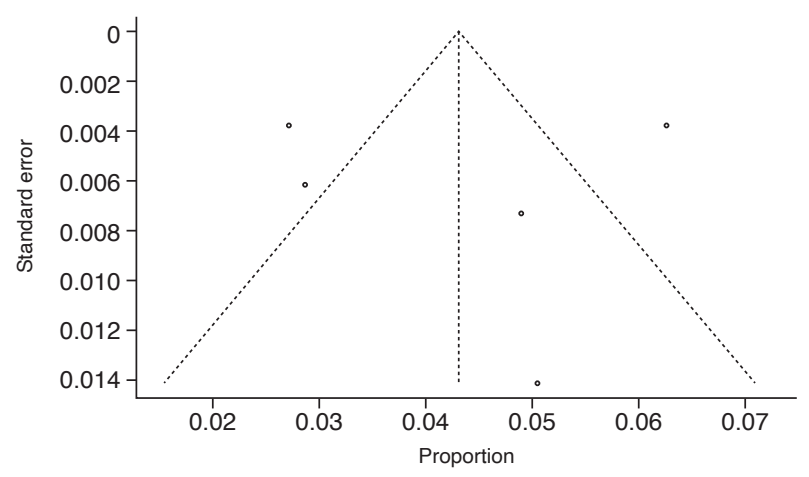

B

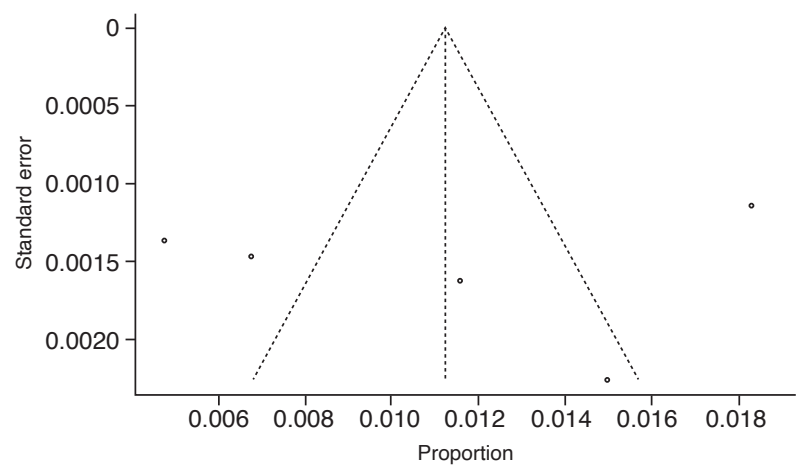

Fig. 4. A funnel plot for meta-analysis of (A) overall pooled percentage of open angle glaucoma among patients with myopia and (B) overall pooled prevalence of myopic open angle glaucoma.

\section{Publication bias}

Fig. 4 shows the present study's funnel plots for indications of publication bias. According to our meta-analysis for the pooled prevalence of OAG among patients with myopia (Fig. 4A) and for overall pooled myopic OAG prevalence in the general population (Fig. 4B), two studies and one study were distributed on the outer left and right sides of the funnel, respectively. Inside the funnel, two studies were distributed to the right. According to this visual depiction of plot symmetry, therefore, publication bias was suspicious. However, Begg and Mazumbar's adjusted rank correlation test showed no evidence of publication bias ( $p$ $=0.62$ ). Even in our meta-analysis of the pooled prevalence of myopic OAG in the general population, no publication bias was found (Begg and Mazumbar's adjusted rank correlation test, $p=0.57$ ).

\section{Discussion}

Myopia has become a major health concern in East Asia [24]. Previous studies have shown similar Japanese and 
Table 5. Characteristics of studies included in the meta-analysis according to the degree of myopia

\begin{tabular}{|c|c|c|c|c|c|c|}
\hline Study & Degree of myopia & $\begin{array}{l}\text { Definition of } \\
\text { myopia degree } \\
\text { (spherical } \\
\text { equivalent in } \\
\text { diopters) }\end{array}$ & $\begin{array}{c}\text { Total sample } \\
\text { size }\end{array}$ & $\begin{array}{c}\text { No. of OAG } \\
\text { patients }\end{array}$ & $\begin{array}{l}\text { Myopia-degree- } \\
\text { specific OAG } \\
\text { prevalence }(\%)\end{array}$ & $\begin{array}{l}\text { Percentage of } \\
\text { OAG among } \\
\text { patients with } \\
\text { specific degree } \\
\text { of myopia (\%) }\end{array}$ \\
\hline \multirow{2}{*}{$\begin{array}{l}\text { Suzuki et al. [21], } \\
\text { the Tajimi study } \\
(2006)\end{array}$} & Low & $<-1.0$ to $>-3.0$ & 389 & 17 & 0.59 & 4.37 \\
\hline & Moderate-to-high & $\leq-3.0$ & 488 & 26 & 0.90 & 5.33 \\
\hline \multirow{3}{*}{$\begin{array}{l}\text { Xu et al. [20], the } \\
\text { Beijing eye study } \\
(2007)\end{array}$} & Low & $<-0.5$ to $\geq-3.0$ & 1,206 & 27 & 0.32 & 2.24 \\
\hline & Moderate & $<-3.0$ to $\geq-6.0$ & 417 & 10 & 0.12 & 2.40 \\
\hline & High & $<-6.0$ & 214 & 13 & 0.15 & 6.07 \\
\hline \multirow{2}{*}{$\begin{array}{l}\text { Perera et al. [23], the } \\
\text { Singapore Malay } \\
\text { eye study (2010) }\end{array}$} & Low & $<-0.5$ to $\geq-4.0$ & 583 & 15 & 0.50 & 2.57 \\
\hline & Moderate-to-high & $<-4.0$ & 148 & 6 & 0.20 & 4.05 \\
\hline \multirow{2}{*}{$\begin{array}{l}\text { Kim et al. } \\
\text { [22], Korea } \\
\text { National Health } \\
\text { and Nutrition } \\
\text { Examination } \\
\text { Survey (2016) }\end{array}$} & Low-to-moderate & $<-0.5$ to $>-6.0$ & 3,797 & 214 & 1.63 & 5.64 \\
\hline & High & $\leq-6.0$ & 242 & 21 & 0.16 & 8.68 \\
\hline
\end{tabular}

$\mathrm{OAG}=$ open-angle glaucoma.

Chinese myopia prevalence to those in other Asian surveys but higher ones than those among white or black populations [25,26]. Glaucoma is the second leading cause of blindness globally [27]. Myopia is a well-known, independent risk factor for OAG [4-6], and certainly, the association between them is a long-standing research interest.

To the best of our knowledge, this is the first meta-analysis of myopic OAG prevalence and OAG prevalence in myopic Asian populations. This study involved a total of 12,830 subjects, among whom were 7,723 patients with myopia and 1,112 with OAG. The pooled OAG prevalence among those with myopia was $4.1 \%$, and the pooled myopic OAG prevalence in the general population was $1.1 \%$.

Within Northeast Asian populations, there has been significant variability in the prevalence of myopic OAG and the proportion of OAG patients among myopia sufferers. Our current results showed that the prevalence of myopic OAG and OAG among myopic patients were the highest in the South Korean population (1.8\% and 6.3\%, respectively). As for the other countries, the prevalence of myopic OAG were $1.5 \%$ in Japan, $0.5 \%$ to $1.2 \%$ in China, and $0.7 \%$ in Singapore (Malay population); the prevalence of $\mathrm{OAG}$ among myopia patients, meanwhile, were $2.7 \%$ to $5.0 \%$ in China, $4.9 \%$ in Japan, and $2.9 \%$ in Singapore (Malay population).
The percentage of OAG among patients with low myopia was $2.24 \%$ to $4.37 \%$, while that with high myopia was $6.07 \%$ to $8.68 \%$. Pan et al. [28] showed that eyes with high myopia had six-fold greater odds of having primary OAG. Although meta-analysis of pooled ORs for glaucoma for different myopia degree was not possible due to insufficient number of studies, such trend of higher percentage of OAG in highly myopic patients agreed with the study by Pan et al. [28].

There is no single conclusion about the influence of ethnicity on refractive error and glaucoma. The effect of refractive error on the risk of primary open-angle glaucoma (POAG) was modestly but significantly stronger in non-Hispanic whites, and its effect on the risk of normal-tension glaucoma was significantly stronger in Asians and non-Hispanic whites [29]. It was also previously suggested that myopia is significant risk factor for POAG among Asians than in white and black populations [20,23,30-35]. In fact, Rudnicka et al. [36] suggested that certain ethnic groups (East Asians) seemed more susceptible to myopia when exposed to the same environmental risk factors for myopia. Our analysis, however, showed that the percentage of OAG among myopic Asian patients $(2.7 \%-6.3 \%)$ was similar to those reported for white populations $(2.9 \%-8.1 \%)[37,38]$. It is interesting that the per- 
centage of OAG among myopia was similar between East Asians and Western Europeans, while the prevalence of myopia is remarkably high among East Asian populations (40\%-70.6\%) compared to that of United States (25.4\%) or Western Europe (26.6\%) [38-41]. Whether such results imply that myopic white patients are more susceptible to develop OAG cannot be concluded. Further research involving more qualified studies from multiple countries, ethnicities and continents should be conducted for more generalized conclusions regarding any ethnic predisposition to myopic OAG.

There are several limitations to the present meta-analysis that need to be acknowledged. First, there was substantial heterogeneity among the studies, which may have resulted from differences in study designs, populations targeted, analysis strategies, and characteristics of participants. The real effects in particular studies may be significantly different from our estimate of overall effect. Rucker et al. [42] mention that baseline or design-related heterogeneity occurs when the population or research design of studies differs between the studies. Five studies included in our study were composed of variable populations in which some only dealt with urban population. The prevalence of normal intraocular pressure in patients with POAG differed by the studies. For example, the prevalence of normal intraocular pressure among POAG patients in Korean population was $95.5 \%$, whereas that in Shanghai population was $70 \%$. Such variation in study population may lead to significant level of heterogeneity in our study. Second, the ways in which the patients had been diagnosed with myopia and OAG differed as well, and as such, some diagnostic bias might have been operative. Third, the major drawback of meta-analyses of studies in general is publication bias. Publication bias might be an issue, because studies that report statistically significant results are more likely to get published than are those that report nonsignificant results, which could have distorted our meta-analysis findings [43]. However, Begg and Mazumbar's adjusted rank correlation test suggested that there was no evidence of publication bias in our study. Fourth, evaluation of glaucomatous structural change in the optic nerve head can be challenging in myopic eyes owing to morphologic characteristics such as tilted disc, peripapillary atrophy, and larger diameters of optic disc $[44,45]$. Non-glaucomatous optic nerve damage also can accompany high myopia [46]. Thus, it needs to be kept in mind that overdiagnosis of glaucoma in myopic eyes might result in overestimation of the prevalence of glaucoma in a myopic population.

In conclusion, we estimated the prevalence of $\mathrm{OAG}$ in a myopic Northeast Asian population and the prevalence of myopic OAG in a general Northeast Asian population. Our findings will inform future glaucoma studies as well as public health guidelines for Northeast Asian populations.

\section{Conflicts of Interest}

No potential conflict of interest relevant to this article was reported.

\section{Acknowledgements}

None.

\section{Funding}

The authors received no financial support for this article.

\section{References}

1. Dolgin E. The myopia boom. Nature 2015;519:276-8.

2. Holden BA, Fricke TR, Wilson DA, et al. Global prevalence of myopia and high myopia and temporal trends from 2000 through 2050. Ophthalmology 2016;123:1036-42.

3. Quigley HA, Broman AT. The number of people with glaucoma worldwide in 2010 and 2020. Br J Ophthalmol 2006;90:262-7.

4. Mastropasqua L, Lobefalo L, Mancini A, et al. Prevalence of myopia in open angle glaucoma. Eur J Ophthalmol 1992;2:33-5.

5. Boland MV, Quigley HA. Risk factors and open-angle glaucoma: classification and application. J Glaucoma 2007:16:406-18.

6. Marcus MW, de Vries MM, Junoy Montolio FG, Jansonius NM. Myopia as a risk factor for open-angle glaucoma: a systematic review and meta-analysis. Ophthalmology 2011;118:1989-94.

7. Ha A, Kim CY, Shim SR, et al. Degree of myopia and glaucoma risk: a dose-response meta-analysis. Am J Ophthalmol 
2021 Oct 11 [Epub]. https://doi.org/10.1016/j.ajo.2021.10.007.

8. Lacroix A. Eye pressure in progressive high myopia in adults. Ann Ocluist 1922;159:730.

9. Diaz-Dominguez D. On the relations of severe myopia and ocular hypertension. Ann Ocul (Paris) 1961;194:597-606.

10. Podos SM, Becker B, Morton WR. High myopia and primary open-angle glaucoma. Am J Ophthalmol 1966;62:1038-43.

11. Stroup DF, Berlin JA, Morton SC, et al. Meta-analysis of observational studies in epidemiology: a proposal for reporting. Meta-analysis Of Observational Studies in Epidemiology (MOOSE) group. JAMA 2000;283:2008-12.

12. Moher D, Liberati A, Tetzlaff J, et al. Preferred reporting items for systematic reviews and meta-analyses: the PRISMA statement. PLoS Med 2009;6:e1000097.

13. Sullivan GM. Irb 101. J Grad Med Educ 2011;3:5-6.

14. Higgins JP, Thompson SG. Quantifying heterogeneity in a meta-analysis. Stat Med 2002;21:1539-58.

15. Higgins JP, Thompson SG, Deeks JJ, Altman DG. Measuring inconsistency in meta-analyses. BMJ 2003;327:557-60.

16. Egger M, Davey Smith G, Schneider M, Minder C. Bias in meta-analysis detected by a simple, graphical test. $B M J$ 1997;315:629-34.

17. Begg CB, Mazumdar M. Operating characteristics of a rank correlation test for publication bias. Biometrics 1994;50:1088-101.

18. The R Foundation for Statistical Computing. R: a language and environment for statistical computing. Version 4.0.4 [software]. 2018 [cited 2021 Dec 14]. Available from: https:// www.r-project.org/.

19. He J, Zou H, Lee RK, et al. Prevalence and risk factors of primary open-angle glaucoma in a city of Eastern China: a population-based study in Pudong New District, Shanghai. BMC Ophthalmol 2015;15:134.

20. $\mathrm{Xu} \mathrm{L}$, Wang Y, Wang S, et al. High myopia and glaucoma susceptibility the Beijing Eye Study. Ophthalmology 2007;114:216-20.

21. Suzuki Y, Iwase A, Araie M, et al. Risk factors for open-angle glaucoma in a Japanese population: the Tajimi Study. Ophthalmology 2006;113:1613-7.

22. Kim KE, Kim MJ, Park KH, et al. Prevalence, awareness, and risk factors of primary open-angle glaucoma: Korea National Health and Nutrition Examination Survey 20082011. Ophthalmology 2016;123:532-41.

23. Perera SA, Wong TY, Tay WT, et al. Refractive error, axial dimensions, and primary open-angle glaucoma: the Singapore Malay Eye Study. Arch Ophthalmol 2010;128:900-5.
24. Morgan IG, Ohno-Matsui K, Saw SM. Myopia. Lancet 2012;379:1739-48.

25. Shimizu N, Nomura H, Ando F, et al. Refractive errors and factors associated with myopia in an adult Japanese population. Jpn J Ophthalmol 2003;47:6-12.

26. Li SM, Liu LR, Li SY, et al. Design, methodology and baseline data of a school-based cohort study in Central China: the Anyang Childhood Eye Study. Ophthalmic Epidemiol 2013;20:348-59.

27. Resnikoff S, Pascolini D, Etya'ale D, et al. Global data on visual impairment in the year 2002. Bull World Health Organ 2004;82:844-51.

28. Pan CW, Cheung CY, Aung T, et al. Differential associations of myopia with major age-related eye diseases: the Singapore Indian Eye Study. Ophthalmology 2013;120:28491.

29. Shen L, Melles RB, Metlapally R, et al. The association of refractive error with glaucoma in a multiethnic population. Ophthalmology 2016;123:92-101.

30. Wang YX, Xu L, Yang H, Jonas JB. Prevalence of glaucoma in North China: the Beijing Eye Study. Am J Ophthalmol 2010;150:917-24.

31. Iwase A, Suzuki Y, Araie M, et al. The prevalence of primary open-angle glaucoma in Japanese: the Tajimi Study. Ophthalmology 2004;111:1641-8.

32. Ramakrishnan R, Nirmalan PK, Krishnadas R, et al. Glaucoma in a rural population of southern India: the Aravind comprehensive eye survey. Ophthalmology 2003;110:148490.

33. Liang YB, Friedman DS, Zhou Q, et al. Prevalence of primary open angle glaucoma in a rural adult Chinese population: the Handan eye study. Invest Ophthalmol Vis Sci 2011;52:8250-7.

34. Jiang X, Varma R, Wu S, et al. Baseline risk factors that predict the development of open-angle glaucoma in a population: the Los Angeles Latino Eye Study. Ophthalmology 2012;119:2245-53.

35. Leske MC, Wu SY, Hennis A, et al. Risk factors for incident open-angle glaucoma: the Barbados Eye Studies. Ophthalmology 2008;115:85-93.

36. Rudnicka AR, Owen CG, Nightingale CM, et al. Ethnic differences in the prevalence of myopia and ocular biometry in 10- and 11-year-old children: the Child Heart and Health Study in England (CHASE). Invest Ophthalmol Vis Sci 2010;51:6270-6.

37. Wong TY, Klein BE, Klein R, et al. Refractive errors, in- 
traocular pressure, and glaucoma in a white population. Ophthalmology 2003;110:211-7.

38. Kuzin AA, Varma R, Reddy HS, et al. Ocular biometry and open-angle glaucoma: the Los Angeles Latino Eye Study. Ophthalmology 2010;117:1713-9.

39. Han SB, Jang J, Yang HK, et al. Prevalence and risk factors of myopia in adult Korean population: Korea national health and nutrition examination survey 2013-2014 (KNHANES VI). PLoS One 2019;14:e211204.

40. Sawada A, Tomidokoro A, Araie M, et al. Refractive errors in an elderly Japanese population: the Tajimi study. Ophthalmology 2008;115:363-70.

41. Kempen JH, Mitchell P, Lee KE, et al. The prevalence of refractive errors among adults in the United States, Western Europe, and Australia. Arch Ophthalmol 2004;122:495-
505.

42. Rucker G, Schwarzer G, Carpenter JR, Schumacher M. Undue reliance on $\mathrm{I}(2)$ in assessing heterogeneity may mislead. BMC Med Res Methodol 2008;8:79.

43. Easterbrook PJ, Berlin JA, Gopalan R, Matthews DR. Publication bias in clinical research. Lancet 1991;337:867-72.

44. Loyo-Berrios NI, Blustein JN. Primary-open glaucoma and myopia: a narrative review. WMJ 2007;106:85-9, 95.

45. Chang RT, Singh K. Myopia and glaucoma: diagnostic and therapeutic challenges. Curr Opin Ophthalmol 2013;24:96101.

46. Jonas JB, Wang YX, Dong L, Panda-Jonas S. High myopia and glaucoma-like optic neuropathy. Asia Pac J Ophthalmol (Phila) 2020;9:234-8. 